\title{
O HUMANISMO E A LINGUAGEM POLÍTICA DO RENASCIMENTO: o uso das Pratiche como fonte para o estudo da formação do pensamento político moderno
}

\author{
Newton Bignotto*
}

\begin{abstract}
Neste texto, pretendemos investigar a utilidade de um conjunto de documentos conservados nos arquivos de Florença para a compreensão da formação e do desenvolvimento do pensamento político renascentista. Estamos nos referindo aos protocolos das Consulte e Pratiche, que eram as reuniões organizadas em Florença para auxiliar os principais órgãos de governo no período que vai de 1494 a 1512. Essas fontes são fundamentais para a compreensão do funcionamento das instituições florentinas no final do século XV, nelas se refletindo um século de cultura humanista e se forjando a nova reflexão política. Pretendemos perguntar pelo uso filosófico que pode ser dado a esses textos florentinos. Ao fim desse percurso, esperamos ter chamado a atenção para alguns temas que podem contribuir para uma melhor compreensão da questão mais ampla da relação entre filosofia política e história.

Palavras-CHAve: Renascimento. Florença. Humanismo.
\end{abstract}

Faz parte do ofício dos historiadores o recurso a fontes documentais de toda natureza. Não ocorreria a um estudioso sério de um determinado período histórico recusar, por exemplo, a importância de documentos conservados em arquivos, ou mesmo de cartas pessoais, que se referem a seu tema. Essa afirmação, banal para os historiadores, não encontra acolhida tão favorável, quando se trata de estudos filosóficos, mesmo entre os historiadores da filosofia. De uma maneira geral, ao se referir às fontes primárias de sua pesquisa, um filósofo profissional está apontando para o conjunto de textos que o guiam e que devem ser secundados pelo recurso às fontes secundárias, $\mathrm{o}$ que, na maior parte das vezes, diz respeito aos muitos comentários existentes sobre um determinado autor ou tema. O recurso a exemplos, ou mesmo a fatos históricos, para auxiliar na demonstração de uma hipótese é algo frequente, mas rara-

\footnotetext{
* Doutor em Filosofia. Professor da Universidade Federal de Minas Gerais. Pesquisador do Conselho Nacional de Desenvolvimento Científico e Tecnológico - CNPq. Av. Antônio Carlos, 6627. Pampulha. Cep: 31270-901
} Belo Horizonte, MG - Brasil.nbignotto@uol.com.br mente escapa do uso instrumental reservado às ferramentas auxiliares da argumentação. Esse é o caso, por exemplo, de lógicos, que inventam situações para facilitar a compreensão do problema que estão tratando, sem, com isso, alterar o percurso de suas demonstrações. Esse procedimento influencia, nos dias de hoje, várias correntes filosóficas e mesmo outros saberes, como é o caso da economia, que fez da teoria dos jogos um instrumento importante de suas investigações. No tocante à filosofia política, o recurso a exemplos históricos é frequente, mas nem sempre fica claro o estatuto epistemológico dos fatos lembrados pelos autores. Com frequência, grandes fatos estão na raiz dos estudos sobre temas como o do contrato social, ou mesmo sobre a natureza dos regimes totalitários, sem que seja dedicada muita atenção ao esclarecimento da importância epistemológica do recurso à história.

Não temos a pretensão de tratar, de forma exaustiva, a questão da relação entre a filosofia política e a história. Tal questão é por demais complexa para o espaço de um texto, e nem mesmo sabemos se podemos formulá-la de forma tão am- 
pla sem incorrer em falsas generalizações. Nossas pretensões, bem mais modestas, referem-se à investigação da utilidade do uso de um conjunto de documentos conservados nos arquivos de Florença para a compreensão da formação e do desenvolvimento do pensamento político renascentista. Estamos nos referindo aos protocolos das Consulte e Pratiche, que eram as reuniões organizadas em Florença para auxiliar os principais órgãos de governo no período que vai de 1494 a $1512 .{ }^{1}$ Nesses encontros, cidadãos notáveis, ou representantes de grupos políticos ou profissionais, eram convocados para opinar sobre questões urgentes e, com isso, participar do processo de decisão, que muitas vezes lidava com questões concernentes à própria sobrevivência da cidade. Essas fontes são fundamentais para a compreensão do funcionamento das instituições florentinas no final do século XV, mas elas contêm mais do que um repertório de falas que precediam a tomada de decisões. Nelas se refletia um século de cultura humanista e se forjava a nova reflexão política. Para formular, no entanto, corretamente uma hipótese de trabalho, é preciso clarear alguns pontos.

Nossa investigação parte da ideia de que o desenvolvimento do humanismo criou uma linguagem capaz de influenciar não apenas os estudiosos da política, mas a própria vida política. Num primeiro momento, vamos tomar essa afirmação como plausível e tentar, de forma sumária, identificar alguns elementos dessa linguagem, lembrando alguns tempos fortes da reflexão de humanistas como Leonardo Bruni. Nossa segunda tarefa consiste em mostrar que, de fato, a língua dos humanistas passou a ser falada não apenas pelos que se interessavam pelos studia humanitatis, mas também pelos participantes mais ativos da cena pública, em particular no período entre 1494 e 1512. Nesse período, a participação nos negócios públicos aumentou de forma expressiva, como resultado da intro-

${ }^{1}$ Para o estudo desses documentos, contamos hoje com as seguintes edições: Fachard, D. (Ed.). Consulte e pratiche. 1505-1512. Genève: Librairie Droz, 1988 Consulte e pratiche della Repubblica Fiorentina. 1498-1505. Genève: Librairie Droz, 1993. 2v.;

Consulte e pratiche della Repubblica Fiorentina.14951497. Genève: Librairie Droz, 2002. dução de novas instituições sob a instigação de Savonarola. Num terceiro momento, vamos nos perguntar pelo uso filosófico que pode ser dado aos textos conservados nos arquivos florentinos, tendo claro que nosso objeto de fundo é o aparecimento de uma reflexão política inovadora durante o Renascimento, e não a história italiana em sua generalidade. De forma mais precisa, interessa-nos estudar a relação entre linguagem política e filosofia no contexto aludido. Ao fim desse percurso, acreditamos que teremos chamado a atenção para alguns temas que podem contribuir para uma melhor compreensão da questão mais ampla da relação entre filosofia política e história.

I

Vamos começar delineando alguns aspectos da língua política florentina. O ponto de partida de nossa investigação foi a constituição do republicanismo cívico renascentista e a preferência que foi acordada em relação à vida ativa, em detrimento da vida contemplativa, que constituíra o núcleo da doutrina cristã medieval. Sob o impacto da leitura dos textos de Cícero, em especial do Tratado dos deveres, e de Tito Lívio, a primeira geração de humanistas - influenciada pelas obras pioneira de Petrarca e depois guiada pelo entusiasmo de Salutati - enfrentou o problema de definir um caminho, que pudesse, ao mesmo tempo, manter os vínculos com o cristianismo e afirmar os valores apregoados pelos autores romanos, que só podiam ser plenamente realizados com a dedicação a atividades vinculadas à vida da cidade. ${ }^{2}$ Petrarca encontrou grandes dificuldades em abandonar o paradigma agostiniano (1999, p.29-48), hesitando, durante toda a vida, entre a herança cristã e o apelo para a participação nos negócios da cidade, que lhe chegavam pelas páginas de Tito Lívio e Cícero, que ele leu e comentou detalhadamente. Com Salutati, as coisas começaram a mudar, embora ainda seja visível a dificuldade do chanceler em ad${ }^{2}$ Um ótimo estudo desse tema segue sendo: Baron, 1988, v.1, cap 6, p. 134-157.

${ }^{3}$ PÉTRARQUE. La vie solitaire. Paris: Payot \& Rivage, 1999 p. $29-48$. 
mitir a tese por ele mesmo defendida segundo a qual a prática da justiça se acorda muito melhor com o cidadão ativo do que com o sábio contemplativo (Baron, 1988, p. 144). ${ }^{4}$

O que devemos reter desse movimento em direção à cidade é que os humanistas descobriram que o espaço público é lugar ideal para a prática de virtudes. Um escrito como o Vita civile de Matteo Palmieri (1982) ${ }^{5}$ representa uma guinada com relação não apenas à contemplação, da forma como era entendida pelos medievais, mas também uma recusa do estoicismo, ou do sábio estoico, como modelo de vida (Baron, 1988, p. 138-141). ${ }^{6}$ Para nós, a herança dos humanistas serve para atentar tanto para o risco da destruição do espaço público, tema recorrente na obra de pensadores contemporâneos como Hannah Arendt, quanto para os riscos da apatia que domina muitas sociedades democráticas contemporâneas. Ao associar valores como liberdade, justiça e outros à ação do cidadão, os humanistas criaram uma tópica essencial do republicanismo moderno.

Vamos agora concentrar nossa atenção em alguns escritos de Leonardo Bruni, chanceler da República Florentina na primeira metade do século XV, que encarnou como poucos o espírito do humanismo em sua vertente cívica. Essa escolha não tem, no entanto, nada de arbitrário. Leonardo Bruni legou-nos um conjunto consistente de escritos nos quais explicitou, de maneira elaborada, as ideias que dominaram o pensamento italiano no começo do século XV e que contribuíram, de forma decisiva, para a consolidação de um novo vocabulário teórico para a filosofia política moderna e para uma nova concepção do homem.

Com Leonardo Bruni, as hesitações que ainda dominavam o pensamento de Petrarca e de Salutati, quanto à relação entre uma vida dedicada à contemplação e a vida ativa, desaparecem completamente. Bruni não opta pelo modelo da vida ativa depois de uma renúncia às suas crenças religiosas,

${ }^{4}$ H. Baron. In search of Florentine Civic Humanism. p. 144. ${ }^{5}$ Matteo Palmieri. Vita Civile. Firenze: Sansoni Editore, 1982.

${ }^{6} \mathrm{H}$. Baron. In search of Florentine Civic Humanism. p. 138-141. ou de um longo debate com as fontes medievais. Ele simplesmente muda os termos do problema, apostando, desde seus primeiros escritos, que sua tarefa principal é pensar os problemas de sua cidade e as dificuldades que ela e todas as repúblicas italianas encontravam para sobreviver no contexto turbulento do começo do século XV na Europa.

O primeiro tema que surge de sua pena é o da origem das cidades e o da criação de sua identidade. Num escrito de alto valor retórico, ele lançou, nos primeiros anos do quattrocento, as bases para uma leitura republicana do passado florentino, que já vinham germinando entre outros eruditos. Seguindo a tendência de seu tempo, ele diz, logo no início da Laudatio Florentine Urbis, que Florença era filha de Roma, da qual "temos exemplos de virtù mais numerosos do que de todas as outras cidades em todos os tempos" (Bruni, 1996, p.596). ${ }^{7}$ A filiação direta ao passado republicano romano era uma tese bastante controvertida do ponto de vista histórico, como constataria, ao longo de sua vida, o próprio Bruni.

O ponto principal da estratégia de Brunique visava, evidentemente, a elevar Florença à condição de cidade livre e gloriosa por meio do elogio de suas muitas características físicas e políticas -é o de fornecer os fundamentos para sua liberdade e sua encarnação nas instituições republicanas através do recurso a acontecimentos do passado que não podiam ser postos em dúvida. Os florentinos, segundo ele, "gozam muitíssimo da liberdade e são fortemente hostis à tirania", ${ }^{8}$ o que se deve, antes de mais nada, às origens livres da cidade. O que interessa, nessa estratégia argumentativa, é menos o fato de que a história de Florença é parcialmente falsificada nas afirmações de Bruni e que seu texto foi escrito como um exercício retórico destinado a suplantar as crônicas medievais que ofereciam uma visão sem relevo da história das cidades, ${ }^{9}$ e mais

7 Leonardo Bruni. Laudatio Florentine Urbis. Opere Letterarie e Politiche. Torino: Utet, 1996. p. 596.

${ }^{8}$ Idem (1996, p. 600).

${ }^{9}$ Como afirma Martines: "If the technical foundations of humanism were in grammar, the high aim was rhetoric, defined as eloquence, as the art of persuasion, or more simply, as the art of the most effective speaking and writing" (1980, p. 194). 
as repercussões de sua démarche.

A grande mudança a ser observada é que a origem da cidade, o que determina sua condição de república livre, oposta às tiranias, situa-se no tempo e não depende de nenhum elemento transcendente para ter validade. Em termos modernos, poderíamos dizer que os humanistas apontaram, ao mesmo tempo, para o fundamento humano da liberdade e para o papel essencial do momento inicial do corpo político. Nesse sentido, pouco importa que o momento inaugural seja o passado romano, o contrato original ou uma revolução. $\mathrm{O}$ que se incorpora à filosofia política é a discussão sobre a origem das cidades e o impacto dessa formulação no papel ativo que os homens desempenham na história. A preocupação com as instituições internas ganha destaque num contexto em que as forças universais - o império e a Igreja não exercem mais um controle efetivo das cidades italianas. Transferir a identidade para a origem significa, ao mesmo tempo, pensar a responsabilidade humana nos destinos dos corpos políticos.

O tema da identidade das cidades sugere que outra tópica do passado pode ser atualizada e fornecer uma base para a estruturação da vida política: a separação do público e do privado. De forma direta, Bruni afirma: "Uma coisa são as culpas públicas, outra as privadas, entre elas há muita diferença. Nas privadas, deve-se atentar para o ânimo daquele que age, nas públicas, para o ânimo de toda a cidade” (Bruni, 1996, p. 614). ${ }^{10}$ Para falarmos de "toda a cidade", é preciso ter em mãos instrumentos que permitam dizer, além das fronteiras geográficas, o que define um corpo político. Bruni perseguirá esse problema ao longo de sua vida. No De Militia, ele propõe uma solução bastante simples, que se liga com a luta das cidades italianas para ficarem livres do domínio das antigas formações com pretensões universais. Para o humanista, "pode-se chamar (um corpo político) de cidade, quando ela pode manter-se por si mesma" (1996, p. 660). ${ }^{11}$ Em outras palavras, o que garante

${ }^{10}$ Leonardo Bruni. Laudatio Florentine Urbis. p. 614.

${ }^{11}$ Leonardo Bruni. De Militia. Opere Letterarie e Politiche. p. 660 a identidade de uma cidade é sua autonomia.

Para os que seriam tentados a ver, na discussão sobre a origem das cidades, um mero exercício literário, Bruni alerta para o fato de que não devemos confundir o momento inicial de fundação com a vida política cotidiana. Assim, diz ele: "é preciso, antes de mais nada, notar que a primeira forma da cidade é determinada pela razão, e a segunda está ligada à fraqueza da condição humana. Para a primeira, é importante a vontade do fundador, para a segunda, a autoridade". ${ }^{12}$ Ou seja, a origem e a vontade do fundador são fundamentais em uma república, mas não determinam o curso de toda vida política. Uma vez constituído o corpo político, após o impulso inicial que confere um rosto à organização institucional, é preciso que ela cumpra suas promessas, dando oportunidade a todos para que, pelo menos, possam esperar alcançar honras e vantagens. Caso contrário, os homens "se deixam tomar pela inércia" (1996, p. 718). ${ }^{13}$ A ordenação institucional é tão ou mais fundamental do que o impulso inaugural, pois uma cidade, que, segundo Bruni, é "uma multidão de homens associados com um conjunto de leis" (p. 660) (14 $^{14}$ só será capaz de garantir a integridade de seu projeto original semigrar para o domíniolegal as razões alegadas pelo fundador para conferir-lhe identidade.

Em termos contemporâneos, podemos dizer que os humanistas abriram as portas para a compreensão dos diversos aspectos envolvidos na fundação de uma cidade ou de um corpo político. Em primeiro lugar, ao mostrar a diferença entre o ato de fundação e a vida institucional, eles contribuíram para a afirmação do valor simbólico do momento inicial. Mais do que ordenar as instituições políticas, o ato de fundação, seja ele um acontecimento do passado, uma revolução, uma "mutação de regime”, como dizia Guicciardini, ou mesmo um mito, é o responsável pela ordenação simbólica do corpo político.

A segunda contribuição para a compreen-

\footnotetext{
${ }^{12}$ Idem (1996, p. 667).

${ }^{13}$ Leonardo Bruni. Oratio in funere Iohannis Strozze. Opere Letterarie e Politiche. p. 718.

${ }^{14}$ Leonardo Bruni. De Militia. p. 660.
} 
são do ato de fundação dada pelos humanistas advém da constatação de que as operações simbólicas não são elas mesmas suficientes para garantir a criação de uma república. Os humanistas procuraram mostrar que o mito de Florença livre dependia, em grande medida, da capacidade de os atores políticos migrarem, para o terreno institucional, as qualidades que atribuíam às origens. Sem essa passagem, a fundação é apenas um ato vazio, que arrisca gerar um caleidoscópio de violência, como aquele de alguns revolucionários modernos, que tentaram, a todo custo, manter vivo um momento cuja função é a de servir de referência simbólica, mas não de se perpetuar em ações contínuas. A verdadeira obra republicana se expressa em leis e no que modernamente chamamos de constituição, que encontra suas raízes no momento inicial e perpetua, sob a forma positiva de instituições, o impulso inicial de liberdade.

Desse projeto inicial, Bruni (1996, p. 716) retirava uma descrição da república florentina que vale a pena citar um pouco mais longamente:

Nós temos uma forma de governo do Estado atenta o mais possível à liberdade e à paridade dos cidadãos. Essa forma de governo, uma vez que é completamente igual para todos, se chama de popular. Nós não suportamos ninguém que seja um patrão, nem estamos submetidos ao poder de poucos. A liberdade é igual para todos, e obedece exclusivamente às leis, sem medo de ninguém. Igual para todos também é a esperança de conseguir elevar-se aos postos mais importantes e receber as honras devidas. Para isso é necessário o talento, o empenho e um modo de vida sábio e ponderado. Nossa cidade procura, em seus cidadãos, virtude e honestidade. Para aqueles que possuem tais qualidades estão abertas as portas para o governo da cidade. ${ }^{15}$

Muitos comentadores já observaram que a descrição oferecida por Bruni, nesse texto que recupera, no Renascimento, a importância das orações fúnebres, ${ }^{16}$ não coincide com a verdadeira ordenação institucional de Florença. A cidade era

${ }^{15}$ Leonardo Bruni. Oratio in funere Iohannis Strozze. p. 716.

${ }^{16}$ A respeito da importância da oração fúnebre na Grécia antiga, ver: Loraux (1994). governada por uma aristocracia que, desde o começo do século XV, lutava para manter o controle dos principais postos de poder. A partir de 1434, esse equilíbrio começou a ser rompido com a ascensão da família Médici, o que distanciou ainda mais a realidade florentina dos ideais republicanos. Mesmo nesse contexto, no entanto, o humanismo foi uma ferramenta importante não apenas para as famílias mais poderosas. (Martines,1980, p. 192) ${ }^{17}$ Bruni demonstra ter consciência disso em um texto no qual descreve, para visitantes estrangeiros, a natureza do governo florentino, quando afirma que "a forma de governo de Florença não é nem aristocrática nem democrática, mas uma mistura das duas" (Bruni, 1996, p. 776). ${ }^{18}$ A compreensão que ele demonstra da maneira como funcionava efetivamente a distribuição do poder em sua cidade nos ajuda a perceber que o republicanismo cívico dos humanistas era uma arma no combate político e uma estrela polar para muitos participantes da vida pública. Os valores defendidos por Bruni, Poggio Bracciolini, ${ }^{19}$ Matteo Palmieri, Alberti ${ }^{20}$ e outros funcionaram como um programa político que demonstrou toda sua força em 1494, quando da queda dos Médici. Diante da possibilidade de reorganizar a vida política da cidade, uma boa parte dos florentinos buscou, nos valores cívicos humanistas, uma referência para a reconstrução das instituições republicanas que haviam perdido paulatinamente suas funções ao longo do período de predomínio mediciano.

O trecho de Bruni que citamos antes nos dá uma ideia clara dos pontos fortes da herança humanista. Estão presentes nele os três eixos principais do pensamento republicano renascentista: liberdade, igualdade e participação. A novidade, no entanto, não está em lembrar a existência desses conceitos e nem mesmo em estatuir a liberda-

\footnotetext{
17 L. Martines. Power and Imagination. City-states in RenaissanceIital. p. 192.

${ }^{18}$ Leonardo Bruni. Sulla costituzione fiorentina. Opere Letterarie e Politiche. p. 776.

${ }^{19}$ Riccardo Fubini. "Il teatro del mondo nelle prospettive morali e storico-politiche di Poggio Bracciolini”" In: Poggio Bracciolini nel VI centenario della nascita. 1380-1980. Firenze: Sansoni, 1982. p. 1-102.

${ }^{20}$ Brandão (2000)
} 
de como o bem maior de uma república, mas de insistir na relação íntima que guardam entre si. De forma esquemática, podemos dizer que os humanistas mostraram que o republicanismo não é uma afirmação unilateral nem da liberdade, nem da igualdade e nem da participação.

Como conclusão desse primeiro movimento, é possível afirmar que o humanismo cívico forjou as bases de uma concepção de política baseada na importância da ação humana na construção das cidades, que deixaram de ser o espaço de espera pelo final dos tempos. Ao ressaltar o caráter ativo da relação dos homens com seu meio, os humanistas apontaram para o lugar de uma política cujo centro se deslocou da eternidade das formas transcendentes para a imanência das cidades. Essa maneira de pensar a política marcou profundamente aqueles que tiveram contato com a cultura humanista e ajudou a forjar a maneira como muitos participantes da vida pública florentina passaram a pensar os grandes problemas de seu tempo.

\section{I}

Feliz Gilbert, num artigo pioneiro, detectou e demonstrou a importância de estudar as ideias políticas do período que vai de 1494 até 1512, por meio do recurso às Consulte e pratiche da república florentina. (1977, p. 67-114) ${ }^{21}$ Em seu trabalho, Gilbert ressalta o fato de que, nas pratiche, travava-se uma intensa batalha política. Nesse sentido, elas se constituíam num local privilegiado do enfrentamento dos diversos grupos políticos que lutavam pelo poder naqueles anos turbulentos da república florentina. Estudar as pratiche permite, segundo ele, acompanhar as ações de uma aristocracia que se via premida entre os elementos mais ligados às camadas populares e os que desejavam o retorno dos Médici. ${ }^{22}$ Considerando, no entanto, o caráter consultivo do órgão e o fato de que os registros do período não são completos, o histori-

${ }^{21}$ Felix Gilbert. Le idee politiche a Firenze al tempo di Savonarola e Soderini. In: Machiavelli e Il suo tempo. Bologna: Il Mulino, 1977, p. 67-114.

${ }^{22}$ Idem, (1977, p. 75). ador recomenda cautela em seu uso como fonte para a história de Florença, embora admita que: "Estudado junto com outras fontes, os protocolos das Pratiche podem ajudar a esclarecer a origem das decisões legislativas e políticas e explicar seu significado". ${ }^{23}$ Além disso, servem como fonte sobre as grandes personalidades políticas do período, sobretudo aquelas mais atuantes na cena pública. ${ }^{24}$ De forma resumida, Gilbert diz: “[...] a Pratica era a magistratura na qual os políticos florentinos construíam sua reputação e se tornavam chefes reconhecidos". ${ }^{25}$

Para o historiador, há uma segunda dimensão da vida política florentina que também está expressa nas Pratiche e que pode ser estudada com muito proveito. Para ele, "uma análise desses documentos pode mostrar em que termos os florentinos pensavam, as ideias e os valores que os dominavam: pode-se fornecer um quadro das concepções políticas presentes em Florença”. ${ }^{26} \mathrm{~A}$ partir dessa consideração, o historiador mostra como os florentinos pensavam a política externa, que papel atribuíam à razão na deliberação política e como pensavam a posição de Florença na cena italiana. Entre outros problemas, abordavam o papel da fortuna nos negócios humanos, misturando essa questão com aquela da providência divina. ${ }^{27}$

No plano interno, o problema da reforma institucional era o mais importante. Preocupados com a instabilidade das formas de mando instituídas depois que os Médici foram expulsos da cidade, os cidadãos florentinos buscaram intensamente compreender como deveriam estruturar seu governo para escapar dos ataques externos, mas também das armadilhas postas pela fortuna $.^{28} \mathrm{Es}-$ ses temas se combinavam com a crença de que Florença era uma cidade especial, escolhida por Deus para levar a cabo uma obra a que nenhuma outra poderia aspirar. Mas essa aspiração e a ideia de que Florença fora escolhida por Deus faziam

${ }^{23}$ Idem (p 77).

${ }^{24}$ Idem (p.77).

${ }^{25}$ Idem (p.79).

${ }^{26}$ Idem (p.79).

${ }^{27}$ Idem (p.95).

${ }^{28}$ Idem (p.100). 
com que os cidadãos pensassem que toda reforma institucional deveria ser um retorno à fundação da cidade, ou à suas instituições, uma vez que elas se revestiam de um caráter divino. ${ }^{29}$ No meio de tempos revoltos e de grandes mudanças, a conservação das formas originais de governo parecia, para muitos, $\mathrm{o}$ ato político mais sensato e transformador, mesmo se isso estivesse longe de ser possível ou de espelhar a realidade política da Itália.

Seja como for, as Pratiche eram momentos fundamentais da vida de Florença, e por elas passaram as grandes personalidades da época. Nelas se travaram os grandes debates que dominaram a vida política da virada do século XV. Gilbert soube reconhecer não apenas a importância dessa instituição, do ponto de vista institucional, mas também o fato de que nela se forjaram os grandes temas que iriam dominar o pensamento político florentino do século XVI. Por isso, assim ele concluiu seu artigo:

As Pratiche são significativas pelo fato de permitirem compreender a revolução operada por Maquiavel no pensamento político. Maquiavel foi um radical porque adotou sempre as ideias mais realísticas e modernas expressas na Pratiche; mas também foi um revolucionário porque sistematizou essas ideias em um sistema lógico, cuja pilastra fundamental é a reavaliação da vontade como uma força política positiva. ${ }^{30}$

Os trabalhos pioneiros de Gilbert deram origem a uma série de estudos baseados nos documentos das Pratiche, dentre os quais podemos identificar, pelo menos, duas grandes correntes. Num primeiro plano, estão os estudos sobre Maquiavel, que aproveitaram as sugestões finais do autor e passaram a combinar a análise dos grandes textos do secretário florentino com o estudo de fontes como as citadas. Embora Tommasini já tivesse iniciado pesquisas nesse sentido, foi, sem dúvida, Genaro Sasso o que melhor aproveitou os documentos das Pratiche para produzir uma nova interpretação da obra de Maquiavel. Na esteira de seus trabalhos, seguiram-se muitos outros tanto

${ }^{29}$ Idem (p. 105).

${ }^{30}$ Idem (p. 108). na Itália quanto em outros países.

Um segundo veio aberto pelo artigo de Gilbert foi aquele das análises da evolução institucional florentina. Antes de Gilbert, Anzilotti já havia se servido das mesmas fontes para estudar a história institucional de Florença, mas foi Giorgio Cadoni quem soube compreender o alcance teórico desse recurso e combinar os estudos históricos com aqueles da formação do pensamento político (1999). ${ }^{31}$ No Brasil, Gabriel Pancera combinou as duas heranças ao se dedicar ao estudo do pensamento institucional de Maquiavel (2010). ${ }^{32}$

Como nosso propósito não é o de fazer o repertório bibliográfico dos últimos anos dos estudos renascentistas, vamos nos contentar com a afirmação de que as indicações fornecidas pelo grande estudioso e a posterior publicação dos arquivos abriram um campo de estudos que está longe de ter se esgotado. Nosso propósito agora, no entanto, não é apenas o de afirmar a fecundidade dos caminhos abertos pelo artigo de Gilbert, mas de sugerir que é possível se servir dos documentos das Pratiche em uma direção que não foi lembrada por ele e que pode se mostrar frutuosa para a história da filosofia política do Renascimento. Trata-se de fazer o movimento com o qual iniciamos no sentido inverso. Ou seja, partimos da ideia de que o humanismo forjou uma nova linguagem política e que essa nova língua impregnou, de forma duradoura, a cena pública florentina do século XV.

É claro que, no espaço de um texto, não podemos levar a cabo o estudo da questão que enunciamos em toda sua extensão. Mais uma vez, nossos propósitos são bem mais modestos e se limitam à demonstração da fecundidade de um procedimento investigativo que toma como ponto de partida essencial o fato de que a linguagem corrente-com a qual as questões políticas são tratadas pelos muitos participantes da cena pública foi efetivamente o ponto de partida da reflexão filosófica dos grandes autores do período, cujas obras

${ }^{31}$ Giorgio Cadoni. Lotte politiche e riforme istituzionali a Firenze tra Il 1494 e Il 1502. Roma: Nella sede dell'Istituto, 1999.

${ }^{32}$ Gabriel Pancera. Maquiavel entre duas repúblicas. Belo Horizonte: Editora da UFMG, 2010. 
dependeram desse terreno para se constituir, mas que, ao mesmo tempo, foi o produto de uma interação entre a linguagem forjada pelos humanistas e a cena política de seu tempo. No fundo, reconhecemos como válida a tese de que a arena pública é o terreno propício para a formação de um pensamento que tenha por referência um conjunto de ideias como aquelas expressas nas Pratiche e que elas se tornam, nesse movimento de constituição e expansão da linguagem política, o local no qual os problemas da filosofia política do período são gestados e no qual se exerce a criatividade dos grandes pensadores. Essa é, em síntese, a tese de Gilbert.

Ora, se não há como negar a fecundidade dos caminhos sugeridos por Gilbert, é mister reconhecer que eles deixam de lado algumas possibilidades de análise quando se adota um ponto de vista mais amplo no estudo das Pratiche. Para o estudioso e muitos de seus seguidores, os protocolos consolidam um terreno a partir do qual é possível visualizar a criação das novas teorias de Maquiavel e Guicciardini, mas eles não se preocupam com os mecanismos de criação da própria linguagem que dominava os debates políticos florentinos. De alguma forma, toma-se a linguagem dos debates como um local de consolidação da opinião pública da época. Gilbert chega a falar de linguagem conceitual dos participantes dos debates, mas continua a omitir o problema da criação dessa linguagem e de seu estatuto teórico.

É possível, a nosso ver, encontrar, nas Pratiche, não apenas o terreno de formação do pensamento político do século XVI, mas também a expressão do impacto direto das ideias políticas desenvolvidas pelos humanistas na cena política da época. Se não aceitarmos tratar os debates apenas como opinião, e sua linguagem como aquela do senso comum, podemos construir um terreno de investigação mais amplo e que coloca a nu o problema da relação entre os desenvolvimentos teóricos humanistas e o de seu impacto na linguagem política da época. Trata-se, portanto, não apenas de reconhecer, em Maquiavel, o herdeiro das Pratiche, como fez Gilbert e tantos outros, mas de ver, nessa instituição, o receptáculo das ideias políticas dos humanistas e os mecanismos de transformação de suas ideias em operadores linguísticos comuns. Nesse movimento, nosso campo de pesquisa se alarga notavelmente, pois passamos a pensar o problema da formação do pensamento político moderno em três tempos inter-relacionados, e não mais como um movimento de dois tempos movidos pelo mecanismo da influência. Esse alargamento do campo de estudos não destrói os resultados obtidos pela via aberta por Gilbert, e nem aquele seguidos, inclusive por nós, ${ }^{33}$ pelos intérpretes de Maquiavel que estudaram sua relação com os humanistas cívicos. Nossa hipótese é de que o reconhecimento da multiplicidade de interações entre o pensamento político e a linguagem política de uma época é uma maneira fecunda para se investigar o problema da relação entre política e pensamento político em uma época determinada. No Renascimento, as Pratiche oferecem o material adequado para levar a cabo os estudos que estamos sugerindo. Do ponto de vista metodológico, embora a analogia do momento vivido por Florença no começo do século XVI com a Revolução francesa requeira alguns cuidados, podemos nos servir do debate sobre a influência do iluminismo e de Rousseau na preparação das ideias revolucionárias como um guia inicial para nossas pesquisas. ${ }^{34}$ Seja como for, as Pratiche abrem um campo de investigação extremamente rico e que está longe de ter sido esgotado pelos trabalhos produzidos até aqui, em que pese o rigor e a riqueza de muitos deles.

\section{I I}

Para tentar ilustrar o que sugerimos antes, vamos analisar alguns documentos, procurando relacioná-los com a primeira parte de nosso texto, quando aludimos aos termos forjados pelos humanistas em sua luta para a formação de uma nova linguagem política em oposição à que havia

\footnotetext{
${ }^{33}$ Em alguma medida, esse foi nosso caminho em: Bignotto (1991).

${ }^{34}$ Ver, a esse respeito, os livros clássicos: Chartier (1990);
} Groethuysen (1956). 
sido herdada do período medieval. Para realizar esse exercício, vamos nos deter em alguns debates, que ocorreram entre o final de junho e o começo de julho de 1502. Referindo-se a esse período, Cadoni diz que: “[...] a cidade se encontrava em condições extremamente precárias, quase desesperada, também por causa da fraqueza estrutural de suas instituições" (1999, p. 153). ${ }^{35}$ Premidos pelas circunstâncias, os florentinos tentaram, de todas as formas, encontrar uma solução para a grave crise pela qual passava a cidade, por meio de reformas institucionais que pudessem, ao mesmo tempo, pacificar os grupos em luta e tornar o poder mais eficaz para enfrentar os múltiplos desafios diante do qual ele estava. O resultado foi um intenso debate sobre a forma de governo, que levou muitos representantes a apresentarem projetos de reforma, os quais, ao final do mês em questão, apenas demonstraram a ruptura interna da cidade e a sua incapacidade de encontrar rapidamente pontos de consenso.

O aspecto principal analisado por Cadoni é a maneira como se desenrolava, em Florença, a luta pelo poder num contexto no qual a própria sobrevivência da liberdade da cidade estava ameaçada. Interessa-nos, mais particularmente, a linguagem na qual os representantes dos diversos segmentos políticos expressavam suas opiniões e como sua visão de mundo era plasmada num vocabulário que misturava diversas influências. Mais especificamente, interessa-nos detectar a presença de uma visão de mundo forjada, em grande medida, no molde conceitual dos humanistas. A existência desse elo entre os conceitos do humanismo, a linguagem da cena pública florentina e o pensamento político do século XVI é nossa hipótese principal. É claro que não se pode pretender que toda a língua política falada em Florença seja fruto da herança humanista. Na fala dos participantes das Pratiche, misturavam-se elementos de crença religiosa, lugares-comuns da época, como o risco de que a parte mais pobre da população poderia se revoltar e comprometer ainda mais a já precária

${ }^{35}$ Giorgio Cadoni. Lotte politiche e riforme istituzionali a Firenze tra Il 1494 e Il 1502. p. 153. estabilidade institucional da cidade, e o medo constante das invasões estrangeiras, o que levava à suposição de que havia um complô permanente dos Médici para retomar o poder. ${ }^{36}$

Vamos acompanhar alguns desses debates e prestar atenção à linguagem de seus participantes. Como não estamos fazendo um estudo sistemático do período, mas apenas indicando uma possibilidade de pesquisa a partir de uma hipótese que amplia o espectro de alguns trabalhos já realizados, vamos nos contentar com a análise de alguns debates entre os dias 5 de julho de $1502 \mathrm{e}$ 20 de julho do mesmo ano. Nessas semanas, as conversas giraram, sobretudo, em torno da necessidade de se realizarem reformas constitucionais. Os debates se iniciaram com as ameaças feitas por César Bórgia, transmitidas por Maquiavel, de que, se não fossem feitas modificações no governo de Florença, ele o consideraria como inimigo, o que, na época, representava uma ameaça bastante real à segurança da cidade. A primeira resposta colocava como ponto de resistência a conservação da liberdade e a necessidade de se evitar o confronto entre cidadãos. ${ }^{37}$ Nela, identificamos dois tópicos da linguagem falada na cena política florentina no último século.

Em primeiro lugar aparece o medo das facções e dos efeitos que as lutas intestinas tinham no interior da cidade. Tratava-se de uma tópica que, com mostrou Francesco Bruni, perdurava na Itália desde o final do século XIII e se manteve ao longo de todo o Renascimento (2003, p. 19-136). ${ }^{38}$ A novidade estava na combinação entre o horror às divisões e a conservação da liberdade. Nesse caso, a presença do sentido humanista da liberdade se faz presente, pois a compreensão que se tem da liberdade nas Pratiche é claramente aquela dos humanistas, que, como vimos, colocava, no centro de suas concepções cívicas, a ideia da liberda-

${ }^{36}$ Idem (1999, p. 157).

37 “...et porre da parte ogni ruggine fussi fra cittadini cittadini , et fare ogni cosa per preservare questa liberta”. S FACHARD, Denis. Consulte e pratiche della Repubblica Fiorentina. 14981505. Genève: Librairie Droz, 1993. v.2, p.811.

${ }^{38}$ Francesco Bruni. La città divisa. Le parti e Il bene comune da Dante a Guicciardini. Bologna: Il Mulino, 2003, p. 19136. 
de como participação e independência. Sabendo da importância que César Bórgia teve na obra de Maquiavel e como ele tratou da questão dos conflitos nos Discorsi, não há como não reconhecer, nos debates do mês de julho de 1502, um cruzamento entre vários atores criadores do pensamento político do Renascimento.

Os participantes de uma pratica falavam por conta própria, ou como representantes de um ofício ou de um grupo social. A identificação dessas vozes é de fundamental importância para o historiador, uma vez que permite recompor a verdadeira face dos conflitos em pauta. Para nós, importa mais reconhecer os traços comuns da linguagem que empregam e observar como as divergências existentes entre os diversos grupos se expressa, ora por meio do recurso a uma terminologia comum, ora por meio de um uso específico de um conteúdo facilmente identificado pelos que debatem. Nesse sentido, não deixa de ser interessante o fato de que quase todos afirmam que, em primeiro lugar, dever-se-ia recorrer a Deus como arma primeira contra as ameaças do Duque. Reconhecemos os traços do período dominado por Savonarola, mas também a crença humanista no destino especial de Florença. O segundo recurso mais citado é a aliança com a França, que deveria servir de proteção nos momentos mais difíceis. A concordância fundamental, no entanto, se expressa na ideia de que o que está em risco é a liberdade. Assim, o peso do pensamento humanista se faz sentir na medida em que a maior parte dos participantes da pratica iguala Florença à sua liberdade e coloca sua defesa em primeiro lugar. À luz do que sabemos sobre o emprego das tropas mercenárias na defesa da cidade e das críticas endereçadas a esse fato por Maquiavel, devemos ser prudentes na interpretação do significado das elocuções. Não podemos, no entanto, desprezar o fato de que o imaginário da cidade era aquele dos humanistas, e é dentro dele que as principais personalidades políticas se expressam.

Na pratica do dia 3 de julho de 1502, Bernardo da Diacceto resumiu o sentimento geral da população dizendo: "Que desde que foi funda- da essa cidade, jamais correu maior perigo, esteve tão desordenada e teve tão pouca reputação quanto no presente. Peço a Deus que nos libere de tantas tribulações" ${ }^{39}$ Seguiu-se à sua fala uma série de intervenções nas quais se misturaram dois elementos: o pedido de intervenção divina e a necessidade de recorrer às doações e empréstimos dos cidadãos para que a cidade tivesse recursos para se defender. O que é interessante, nesse caso, é que, apesar da presença da ideia reguladora da fundação livre da cidade estar presente nas falas de muitos participantes da pratica, a necessidade de salvar Florença expõe uma concepção da situação que combina elementos totalmente díspares. De um lado, o apego a um mito religioso que havia tido seu auge alguns anos antes, quando Savonarola reinava sobre os espíritos. De outro, o agudo senso de realidade de homens de negócio que temiam, sobretudo, o risco que corria seu patrimônio. Nesse caso, o humanismo fornece a linguagem para se compreender a identidade histórica da cidade, mas é deixado de lado tanto como linguagem da esperança quanto como linguagem da prática política. Curiosamente, é desse "fracasso" do humanismo do século XV em consolidar uma ideário político republicano baseado na ação dos cidadãos que vão nascer tópicos centrais na obra de Maquiavel, como sua crítica à ideia de que o dinheiro é o núcleo da guerra. Retomando a crença humanista de que um exército de cidadãos é o mais adequado para assegurar a defesa da cidade, ele garante a continuidade teórica da tradição republicana e realiza a crítica daqueles que, em seu tempo, faziam do dinheiro o núcleo da relação dos cidadãos com sua cidade. Guido Mannelli resume muito bem essa maneira de pensar, quando, depois de lembrar os males de seu tempo, diz que: "para remediá-los, a ele ocorre que se deve pensar em todos os meios mediante os quais se possa conseguir dinheiro". ${ }^{40}$

Se, nas discussões anteriores, as ameaças de César Bórgia foram rechaçadas em nome da liberdade da cidade, na pratica do dia 5 de julho, começaram a aparecer discursos nos quais o problema do

${ }^{39}$ Fachard (1993, v. 2 p. 816).

${ }^{40}$ Idem (1993, v. 2, p. 818). 
ordenamento institucional e do funcionamento atual do governo ocupava a posição central. Antonio Benivieni dizia, referindo-se aos problemas recentes e às perdas territoriais da república, "que isso parece proceder em virtude da desordem e do mau governo, muito mais do que por outras razões e a ele ocorre perguntar se deviam mudar o modo de viver e de governar" ${ }^{41}$ Essa foi a deixa para que o problema da forma de governo ocupasse o centro das discussões. Na verdade, desde a expulsão dos Médici, esse foi o terreno no qual a luta pelo poder se desenrolou e definiu os contornos institucionais da cidade. Não é de se admirar, portanto, que, nesse dia, Bernardo Rucellai tenha tomado a palavra para defender a reforma da república e para sugerir o governo de Veneza como o modelo a ser seguido. Figura central do grupo social que se identificava como os ottimati, ele não desejava o retorno dos antigos detentores do poder, mas via, na forma veneziana de governo, uma maneira eficaz de devolver o poder aos aristocratas, ao mesmo tempo em que conservava a república como referência.

Nesse debate sobre a forma de governo, o humanismo forneceu os operadores centrais e apontou para a liberdade e a participação dos cidadãos como o eixo de toda república. Fugir desse paradigma conceitual significava recusar a república e escolher uma forma de governo que só podia ser tirânica. Esse era o terreno comum da discussão, e dele não se afastavam nem mesmo os líderes dos ottimati. Dentro desse molde, no entanto, cabiam diversas interpretações dos princípios republicanos, e é em torno delas que a luta política se desenrolava.

Um mostra da prevalência do discurso humanista na linguagem dos homens públicos florentinos, quando se tratava de discutir as formas de governo, aparece na pratica do dia 6 de julho. Nela, quatro dos principais bairros de Florença propuseram seus modelos institucionais, para fazer face aos problemas vividos pela cidade. Falaram os representantes dos quartieri de Sancto Spirito, Sancta Croce, Sancta Maria Nuova, e San

${ }^{41}$ Idem (p. 819).
Giovanni. As discussões recaíram sobre os detalhes da organização das instituições e sobre sua composição. No fundamento de cada uma das propostas, estava a escolha de um modo de governo que admitisse maior ou menor participação da população, que fosse stretto ou largo. Essa era a maneira como os humanistas, desde Bruni, pensavam a questão da melhor constituição republicana. Esse será o ponto de partida dos debates teóricos travados pela próxima geração de teóricos liderados por homens como Maquiavel, Guicciardini e Giannotti, como mostrou Pancera em seus estudos.

As Pratiche não foram, assim, apenas o espaço de discussão de uma cidade que se mostrava preocupada com seu destino e se servia de uma linguagem ordinária para se comunicar. Nelas, a herança humanista consolidou sua influência e preparou o nascimento de novas formas de pensamento político. Na corrente de transmissão entre o humanismo, em sua dimensão cívica, e o pensamento de autores como Maquiavel e Guicciardini, as Pratiche são o lugar de transformação de uma reflexão teórica em patrimônio linguístico e conceitual de toda uma comunidade, que escolheu falar uma língua para entender seus problemas e dilemas. Ao mesmo tempo, confrontar essa língua com a realidade política do tempo contribuiu para colocar à prova seus principais operadores. Nesse sentido, a crítica realista de Maquiavel e de Guicciardini ao pensamento de seus contemporâneos é tanto mais vigorosa porque não se ancora num simples debate de ideias, mas finca raízes nos conflitos efetivos que dilaceravam sua época. As Pratiche oferecem, assim, a possibilidade de estudarmos, de maneira consistente, a formação e a transmissão de uma herança conceitual e as articulações que tornam possível a criação de uma nova teoria política, distante e, ao mesmo tempo, em sintonia com uma herança que se constituiu tanto em um conjunto de obras teóricas quanto em linguagem política dominante de uma época.

Recebido para publicação em 15 de julho de 2012 Aceito em 04 de novembro de 2012 


\section{REFERÊNCIAS}

BARON, H. In search of Florentine civic humanism. Princeton: Princeton University Press, 1988. v.1, cap 6. p.134-157 ; 144, 138-141.

BIGNOTTO, Newton. Maquiavel republicano. São Paulo: Loyola, 1991.

BRANDÃO, Carlos Antônio Leite. Quid tum? O combate da arte em Leon Battista Alberti. Belo Horizonte: Editora da UFMG, 2000.

BRUNI, Francesco. La città divisa. Le parti e Il bene comune da Dante a Guicciardini. Bologna: Il Mulino, 2003. p. 19136.

BRUNI, Leonardo. Laudatio Florentine Urbis. Opere Letterarie e Politiche. Torino: Utet, 1996. 896p. p. 596.

De Militia. Opere Letterarie e Politiche. Torino: Utet, 1996. p.660

Oratio in funere Iohannis Strozze. Opere

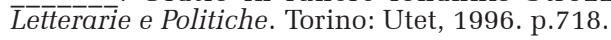

Sulla costituzione fiorentina. Opere Letterarie e Politiche. Torino: Utet, 1996. p.776.

CADONI, Giorgio. Lotte politiche e riforme istituzionali a Firenze tra Il 1494 e Il 1502. Roma: Nella sede dell'Istituto, 1999. p.153, 157
CHARTIER. Roger. Les origines culturelles de la Révolution française. Paris: Éditions du Seuil, 1990.

FACHARD, Denis. Consulte e pratiche della Repubblica Fiorentina. 1498-1505. Genève: Librairie Droz, 1993. v.2. p.811, 816, 818, 819 .

GILBERT, Felix. Le idee politiche a Firenze al tempo di Savonarola e Soderini. In: ___ Machiavelli e Il suo tempo. Bologna: Il Mulino, 1977. p. 67-114.

GROETHUYSEN, Bernard. Philosophie de la révolution française. Paris: Gallimard, 1956.

LORAUX, Nicole. A invenção e Atenas. Rio de Janeiro: 34 Letras, 1994.

MARTINES, L. Power and imagination. City-states in Renaissance Iital. New York: Vintage Books, 1980. p. 194.

PALMIERI, Matteo. Vita civile. Firenze: Sansoni Editore, 1982.

PANCERA, Gabriel. Maquiavel entre duas repúblicas. Belo Horizonte: Editora da UFMG, 2010.

PÉTRARQUE. La vie solitaire. Paris: Payot \& Rivage, 1999. p 29-48. 
THE HUMANISM AND THE POLITICAL LANGUAGE OF THE RENAISSANCE: the use of the pratiche as source to the study of the formation of modern political thought

\section{Newton Bignotto}

We wish to address the usefulness of a set of documents which are conserved in the archives of Florence to the understanding of the birth and development of Renaissance political thought. These are the protocols of the Consulte e Pratiche, which were meetings organized in Florence to help the main government organs of the period spanning from 1494 to 1512 . These sources are crucial to the understanding of the operation of Florentine institutions from the late XVth. Century. In them we can see the echoes of a century of humanistic culture, and the forging of the new political reflection. We want to explore the philosophical use that can be made of these Florentine texts. Our hope is that of drawing attention to a couple of themes that can contribute to a better understanding of the wider question of the relation between political philosophy and history.

KEY-wORDS: Renaissance. Florence. Humanism.

\section{L'HUMANISME ET LE LANGAGE POLITIQUE DE LA RENAISSANCE: I'utilisation des Pratiche comme source pour l'étude de la formation de la pensée politique moderne}

\section{Newton Bignotto}

Il s'agit dans ce texte de vérifier l'utilité d'un ensemble de documents conservés dans les archives de Florence pour comprendre la formation et le développement de la pensée politique de la Renaissance. Nous faisons référence aux protocoles des Consulte e Pratiche c'est-à-dire aux réunions organisées à Florence pour aider les principaux organes du gouvernement dans une période qui va de 1494 à 1512. Ces sources sont fondamentales à la compréhension du fonctionnement des institutions florentines à la fin du XVe siècle où l'on peut voir le reflet d'un siècle de culture humaniste et les bases d'une nouvelle réflexion politique. Notre intention est de connaître l'usage philosophique qui peut être attribuéà ces textes florentins. A la fin de ce parcours, nous espérons que certains thèmes feront l'objet d'une attention spéciale et pourront contribuer à une meilleure compréhension dela question plus étendue concernant la relation entre la philosophie politique et l'histoire.

Mots-CLÉs: Renaissance. Florence. Humanisme.

\footnotetext{
Newton Bignotto - Doutor em Filosofia. Professor da Universidade Federal de Minas Gerais. Pesquisador do Conselho Nacional de Desenvolvimento Científico e Tecnológico - CNPq. Tem experiência na área de Filosofia, com ênfase em História da Filosofia. Atua principalmente nos seguintes temas: Republicanismo, Maquiavel, Liberdade, Fundação. Publicações recentes: Um convite a pensar a liberdade. Ciência Hoje, São Paulo, SBPC, v.1, p.76-77, 2013; Republicanismo, Constituição e percepção da justiça no Brasil. Ideias, Campinas, UNICAMP, v.1, p.34-53, 2012; Matrizes do republicanismo (Organizador). Belo Horizonte: Ed. UFMG, 2013. 314p; As aventuras da virtude. São Paulo: Companhia das Letras, 2010. 393p v.1
} 
